\title{
How does STICS crop model simulate crop growth and productivity under shade conditions?
}

\author{
S. Artru ${ }^{\mathrm{a}, *, 1}$, B. Dumont ${ }^{\mathrm{a}, 1}$, F. Ruget ${ }^{\mathrm{b}}$, M. Launay ${ }^{\mathrm{c}}$, D. Ripoche ${ }^{\mathrm{c}}$, L. Lassois $^{\mathrm{a}}$, S. Garré $^{\mathrm{a}}$ \\ a Université de Liège, Gembloux Agro-Bio Tech, Terra Research Center, AgricultureIsLife, Passage des deportés 2, 5030 Gembloux, Belgium \\ b UMR1114 EMMAH, INRA, centre de recherche PACA, 228 route de l'Aérodrome, Domaine Saint Paul, Site Agroparc, 84914 Avignon, France \\ ' US1116 AGROCLIM, INRA, centre de recherche PACA, 228 route de l'Aérodrome, Domaine Saint Paul, Site Agroparc, 84914 Avignon, France
}

\section{A R T I C L E I N F O}

\section{Keywords:}

STICS model

Agroforestry

Shade

Winter wheat

Grain yield

Grain number

\begin{abstract}
A B S T R A C T
Most crop models have been developed with crops growing under full sunlight conditions and they commonly use daily cumulated global radiation as part of the climatic input data. This approach neglects the spatio-temporal dimension of the light reduction experienced by the crop in agroforestry systems. In this study, we evaluate the ability of the crop model STICS to predict winter wheat (Triticum aestivum L.) growth and yield under three distinct light conditions using field observations from a two year artificial shade experiment. The shade structure induced a continuous shade (CS) treatment characterized by a reduction of the proportion of light during the entire day and a periodic shade (PS) treatment defined by an intermittent shade varying on the plot throughout the day. These two shade conditions were compared to a no shade treatment (NS) receiving $100 \%$ of the available light. The model accurately predicted the timing of the grain maturity stage under the PS treatment by reducing the daily global radiation only. A correct prediction of this growth stage in the CS treatment required a decrease of the daily maximum air temperature in addition to the reduction of global radiation. Overall, the model accurately reproduces the total aboveground dry matter dynamics under the CS and NS treatments, but did not simulate the reduction observed under the PS treatment correctly. Three parameters (nbjgrain, cgrain and cgrain $_{v o}$ ) involved in the determination of the number of grains have been calibrated with the NS treatment data and were then used to predict the crop behavior under the shaded treatments. Using this adjusted parameter set, the STICS model gave a good prediction of the grain number under all treatments. Nevertheless, the simulation of final grain yield under the shade treatments was not satisfactory yet, presumably due to an overestimation of the reallocation of the biomass between shoots and grains. Improving the prediction of these reallocation processes is challenging and critical to improve the simulation of crop behavior under fluctuating light environments such as encountered in agroforestry systems.
\end{abstract}

\section{Introduction}

Within silvoarable agroforestry systems, defined here has the integration of tree rows within cropped area, the presence of a tree canopy reduces the incident light for the crop and induces a heterogeneous spatio-temporal light pattern, next to the competition for water and nutrients. At the daily time scale, the tree canopy induces a dynamic light environment according to the path of the sun, the field configuration, the species choice and tree management (Liu, 1991). At the growing season time scale, the crop is subjected to an intensification of shade following the tree phenology and leaf apparition. Finally, the light environment evolves over the years according to the tree growth. These effects can be minimized using well-thought implantation of the trees with respect to the sun path, an appropriate tree density and an adapted tree species choice and management (Cannell et al., 1996; García-Barrios and Ong, 2004), even though they cannot be totally removed. In order to support a better management of new agroforestry systems in Europe, it is important to quantify and predict the potential impact of this specific light environment on crop productivity, since light is involved in most plant processes (e.g. photosynthesis or transpiration).

Field experiments remain time-consuming and expensive, because of the numerous potential combinations between tree and crop species, the variety of pedo-climatic environments and practices as well as the long term dynamics of these mixed systems (Knörzer et al., 2011). In this context, crop models are powerful research tools that can help to

\footnotetext{
* Corresponding author.

E-mail address: artru.sidonie@gmail.com (S. Artru).

${ }^{1}$ These authors contributed mainly to this work.
} 
improve our understanding of crop growth under reduced light conditions. Since extended time series and various conditions can be simulated, they can integrate climatic variability and long term effects (Dumont et al., 2015; Palosuo et al., 2011). Crop models can also be used to evaluate different field designs (Talbot, 2012) and management strategies for agroforestry (Chimonyo et al., 2015).

In a recent review, Luedeling et al. (2016) give an overview of eight existing models or modelling frameworks for agroforestry systems. Most of these models share a common general framework, but they can be classified according to the level of complexity with which the processes are described. Firstly, we can separate process-based from empirical models. Process-based models describe the crop and tree growth in interaction with it is environment in terms of biophysical laws, whereas empirical models use mathematical relationships independent from these laws and obtained through experimental observations. A second important difference is the spatio-temporal discretization used by the model. Since questions can arise on the one hand on interactions at the daily timescale and on the other hand on long term effects ( $>20$ years), the models should maintain a balance between the accuracy with which single processes are described, the system approach and the computation time (Leroy et al., 2009; Malézieux et al., 2009; Roupsard et al., 2008) and therefore the discretization level should be adapted to the modelling objectives.

In a review comparing representative multi-species system models, Malézieux et al. (2009) separated models implementing a process description at a yearly (Yield-SAFE, COMMIX, SORTIE/BC, SexI-FS) and daily time step (CROPSYS, STICS, GEMINI, WaNuLCAS, Hi-sAFe). However, even the daily time step is rather large if one needs to take into account specific physiological reactions of plants to changes in their environment. Since the light environment in agroforestry systems can change considerably during the day, a time step even smaller than a day could be necessary to take into account the biophysical consequences of this environment. Models running at a daily time scale inherently neglect the daily spatio-temporal dynamics existing in agroforestry systems. Typically, in such models the radiation received by the crop is summarized by the daily cumulated global radiation. Nevertheless, several studies highlighted that a decrease in vegetative growth is observed under a fluctuating and heterogeneous light environment, the decrease in biomass being however not proportional to the light reduction (Artru et al., 2017; Dufour et al., 2013; Liu, 1991; Pearcy et al., 1996; Peri et al., 2002). From a physiological point of view, daily biomass growth of plants growing in a complex light environment can therefore not be estimated correctly from a daily cumulated value of the global radiation. This raises questions about the ability of the existing agroforestry models to correctly predict crop growth under agroforestry conditions especially in climatic regions where competition for light becomes important.

Furthermore, van Noordwijk and Lusiana (1999) highlighted that linking separately developed models to simulate mixed cropping systems has its limitations, even if these models are process-based. They argued that the effects of above- and below-ground resource competition is generally more pronounced under monocropped systems, since these systems were not forced to develop strategies for resource sharing between species and therefore models developed in this context do not include specific mechanisms to do this. Moreover, plants can respond to environmental changes by undergoing morphological and/or physiological changes compensating for limiting conditions in order to maintain crop growth; e.g. a change in leaf area or leaf shape during the leaf development can occur in response to a reduced light environment (Murchie and Niyogi, 2011; Peri et al., 2002; Retkute et al., 2015). If a part of the mixed cropping model has been previously developed and calibrated under full light monocropped conditions, the risk is to use a model outside its range of validity (e.g. a reduced light environment), which can lead to an over- or underestimation of crop growth.

Within the models presented by Luedeling et al. (2016) the model $\mathrm{Hi}$-sAFe is one of the most advanced, physically-based model linking the different components involved in an agroforestry system. This model was designed to simulate trees and crops species interaction and management strategies in temperate regions. Within Hi-sAFe, the STICS crop model is combined with a tree growth model in order to be able to assess the interactions between the two components. STICS has already been validated under full light conditions (Coucheney et al., 2015) but never under shaded conditions while within silvoarable agroforestry system, implementing an east-west tree line orientation induces a high degree of light heterogeneity for the crop. In fact, in this configuration, the field can be subdivided in three different shade areas subjected to: (i) a dense and continuous shade during the day near the trees, (ii) a dynamic shade in the afternoon, and (iii) a shade-free zone according to the path of the sun. In this context, this paper deals with two specific research questions: Using STICS crop model (i) Is it possible to predict the response of winter wheat to these different light conditions, using a single and common plant parameter set? (ii) Is the daily cumulated global radiation sufficient as the main driver to simulate the development of winter wheat subjected to periodic shade?

The aim of the present study is to assess the ability of the STICS crop model (Brisson et al., 2008), to accurately predict winter wheat ( $T$. aestivum L.) development and final productivity under an artificial reduced heterogeneous light environment.

\section{Material and methods}

\subsection{Field experiment and data set}

During two consecutive growing seasons (2014-15 and 2015-16), winter wheat (T. aestivum L., cultivar Edgard) was sown at the experimental farm of Gembloux Agro-Bio Tech $\left(50^{\circ} 33^{\prime} \mathrm{N}, 4^{\circ} 42^{\prime} \mathrm{E}\right)$, in the Hesbaye region, Belgium. In the two consecutive years, the experimental plots were not exactly at the same location in the field due to crop rotation management. Nevertheless, they were both located on a Luvisol (WRB, FAO, 2014). The climate is temperate maritime, with an average annual temperature of $9.96{ }^{\circ} \mathrm{C}$ and mean annual cumulated rainfall of $805 \mathrm{~mm}$ over the last 30 year (1986-2015). The weather conditions of both growing seasons were highly contrasted in terms of rainfall and global radiation. The first growing season was characterized by a relatively dry and sunny spring (mean global radiation: $557 \mathrm{MJ} / \mathrm{m}^{2}$ and mean rainfall $43 \mathrm{~mm}$ from April to June), while the second was wetter with lower radiation in spring (mean global radiation: $472 \mathrm{MJ} / \mathrm{m}^{2}$ and mean rain fall $102 \mathrm{~mm}$ from April to June) (Fig. 1c \&d).

The seeds were sown on October 21th, 2014 (250 grains $\left./ \mathrm{m}^{2}\right)$ and on October 27th, 2015 (300 grains $/ \mathrm{m}^{2}$ ) following an East-West orientation in both cases. The preceding crops were rapeseed (Brassica napus L.) in 2014-2015 and chicory (Cichorium intybus L.) in 2015-2016. Fertilization followed the conventional practice applied in Belgium, which means that three doses of nitrogen fertilizer were applied throughout the growing season (75/75/75 in 2014-15 and 60/60/75 in 2015-16) respectively at Zadoks stages 26, 30 and 58.

In this field experiment, we applied artificial shade to the crop using a greenhouse tunnel $(68 \times 5 \mathrm{~m})$ installed in the field with an East-West orientation and military tarps disposed on the southern face of the structure. Based on the path of the sun, this resulted in three shade levels corresponding to three distinct types of daily shade dynamics. The continuous shade (CS) treatment reduces the proportion of light during the entire day. The periodic shade (PS) treatment received an intermittent shade. The shade structure orientation and the path of the sun induce a moving shade on the plot during the day along the northsouth gradient. The no shade treatment (NS) received $100 \%$ of the available light. Camouflage net was used as shade material to reproduce a fluctuating sun/shade pattern, the holes in the cloth producing a combination of direct and diffuse light patches. The application of different shade layers followed the increasing shade produced by the canopy of a late-flushing tree. As such, we monitored the phenological 

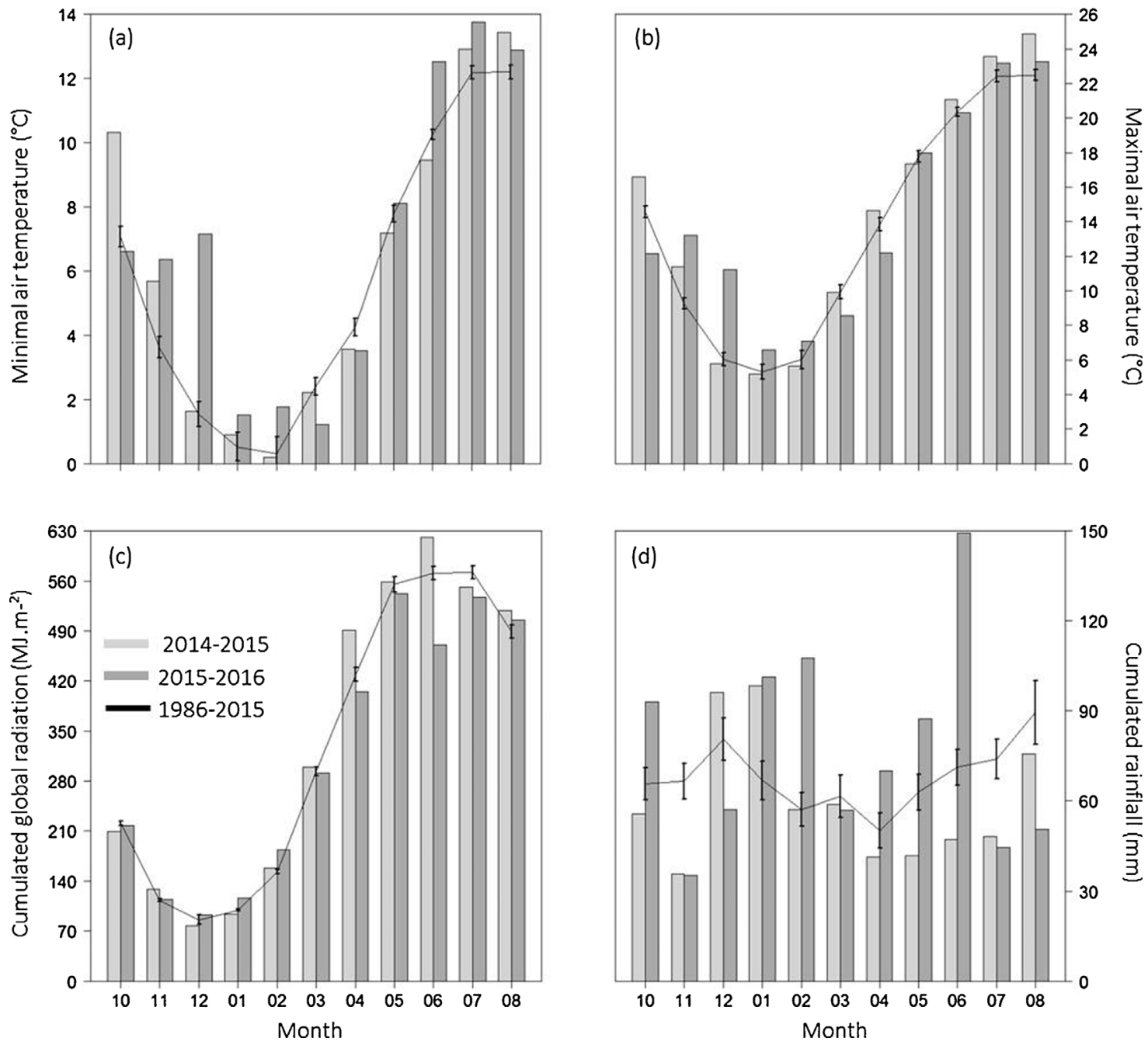

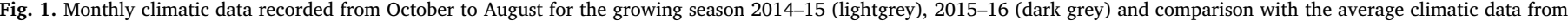

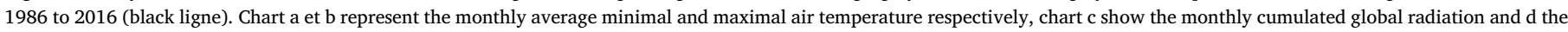
cumulated rainfall. Vertical bars represent the standard error of the means of the mean data.

development of 60 hybrid-walnut trees located in a plantation in Jenneret, Condroz region, Belgium $\left(50^{\circ} 24^{\prime} \mathrm{N}, 5^{\circ} 27^{\prime} \mathrm{E}\right)$. To mimic the walnut tree leaf expansion, we applied a first layer of camouflage net after budburst when tree induces a significant shade (visual appreciation) and a second layer at the end of the maximal leaf expansion. In 2014-15, the first layer of shading was imposed 226 days after winter wheat sowing (DAS, June 4th) and the second from 245 DAS (June 23th) until harvest 292 DAS (August 10th). In 2015-16, the first layer was applied 218 DAS (June 2th) and the second from 240 DAS (June 23th) until harvest 289 DAS (August 11th). According to the observed hybrid walnut and winter wheat phenology, the artificial shade layers were applied 10 days and 7 days before wheat flowering for the growing season 2014-15 and 2015-16, respectively.

Both growing seasons, daily climatic data (air temperature and humidity, rainfall, wind speed, wind direction and global radiation) were recorded by a weather station from the Royal Meteorological Institute, located $3 \mathrm{~km}$ from the experimental site (Ernage, Gembloux, $\left.50^{\circ} 59^{\prime} \mathrm{N}, 1724^{\circ} 67^{\prime} \mathrm{E}\right)$. Under each treatment, incident global radiation was recorded using quantum sensors (CS300 - Campbell Scientific Inc., USA - accuracy \pm 5 for the daily global radiation) installed above the crop canopy level. The global radiation intercepted by the whole PS plot was calculated using a spatial average of the global radiation intercepted by three light sensors installed along a North-South gradient. During the growing season, crop phenology, aboveground biomass (sum of straw and spike dry matter biomass), final grain yield and yield components (grain number per $\mathrm{m}^{2}$ and grain weight) were monitored (6 measurements in 2014-15 and 2 measurements in 2015-16). Aboveground biomass ( $\mathrm{t} / \mathrm{ha}$ ) was assessed four (June 18th) and seven (June 21th) days after flowering in 2015 and 2016 respectively, as well as the 7th of August in 2015 and the 8th of August in 2016 when all the treatments had reached maturity. The sampling corresponds to three adjacent rows of $40 \mathrm{~cm}$ length at flowering and $50 \mathrm{~cm}$ at maturity stage. The measurements were performed on dried samples. More details on the experimental setup are published in Artru et al. (2017).

\subsection{Model set up}

\subsubsection{Structure of the STICS crop model}

The STICS crop growth model (STICS v8.4, INRA, France) is fully described in the literature (Brisson et al., 2008) and validated for a broad range of crop species (Coucheney et al., 2015). It is a generic crop model that simulates the soil-plant-atmosphere system dynamics on a daily time step. The crop is characterized by its leaf area index (LAI), its above-ground dry biomass as well as the number and the biomass of the harvested organs. The duration between each physiological stage (e.g. emergence, flowering, and maturity) is partly driven by the sum of degree-days and is based on crop temperature derived from air temperature using the energy balance approach. Other factors such as the soil temperature and humidity at the rooting depth as well as 
vernalization requirement are implemented as reduction factors in the definition of the daily phasic development of the crop.

In this study, we were interested in the productivity of winter wheat crop under different 'light environments'. The main formalisms of interest are the aboveground biomass dynamics, the setting of the grain (grain number) and the grain filling process. Thus, we focused our study on the total aboveground biomass and end-season variables such as grain yield, grain number per $\mathrm{m}^{2}$ and grain weight amongst all the available output variables within STICS. The total aboveground biomass (masec, $\mathrm{t} / \mathrm{ha}$ ) simulated by STICS relies on the accumulation of the daily biomass production (dltams $\mathrm{t} / \mathrm{ha}$ ). This accumulation is driven by the concept of radiation use efficiency and takes into account several stress factors influencing crop growth processes such as thermal, hydric and nutritive stresses. Final grain yield (mafruit, t/ha) is defined through two main phase: first the grain number (nbgrains, grains $/ \mathrm{m}^{2}$ ) is determined before flowering and then the grain filling (daily accumulation of biomass into the grains) occurs between flowering and maturity. The grain number is a function of vitmoy $\left(\mathrm{g} / \mathrm{m}^{2} / \mathrm{d}\right)$ defined as the aboveground biomass growth rate (dltams, t/ha/d) during a fixed period prevailing flowering (nbjgrain, days). This relation relies linearly on two shape species parameters cgrain and $\operatorname{cgrain}_{v o}$ and the grain number is limited by two plant parameters that constrain the number of grains with boundaries: nbgrmax and nbgrmin. The daily accumulation of biomass into the grains (dltags in t/ha) is calculated by applying a dynamic harvest index (ircarb) to the total aboveground biomass. In the option we chose, this harvest index increases as a linear function of the thermal time from flowering to maturity and depends on the viticarb (g.grain/g/d) parameter. Finally, grain weight (pgrain, g) is calculated as the ratio between the final grain yield (mafruit) and the grain numbers (nbgrains). This variable cannot exceed a varietal limit, defined by the threshold parameter pgrainmaxi. A complete description of the formalisms is available in Brisson et al. (2008). The variables of interest and parameters presented below are synthetized Table A1 in Appendix A.

\subsubsection{Model parametrization and cultivar selection}

To run a simulation with STICS, daily climatic input data as well as soil, management and plants parameters are required. In this study, input weather data files including daily minimum and maximum air temperature, relative humidity, rainfall, wind speed, wind direction and global radiation, were created from the data obtained from the Royal Meteorological Institute weather station, located $3 \mathrm{~km}$ from the experimental site (Ernage, Gembloux, 50 $59^{\prime} \mathrm{N}, 1724^{\circ} 67^{\prime} \mathrm{E}$ ). As soon as the shade structure was set up, we used data recorded under the different light treatments (NS, PS, and CS) to replace the daily global radiation of the Ernage station. The potential evapotranspiration was calculated with the Shuttleworth-Wallace equation (Brisson et al., 1998). This equation is based on a resistive approach which accounts for the convective conditions around the plants and is appropriate for crops growing under a fluctuating microclimatic environment such as observed under agroforestry systems.

Soil input parameters were obtained from soil analysis or derived from basic soil measurements (Table 1). Pedotransfer functions have been used to define the gravimetric water content at field capacity and at wilting point for each soil layer (Jones et al., 1991). Moreover, the model is able to take into account the detrimental impact of root zone anoxia due to temporary excess of water on the shallow soil, which was particularly relevant given the high amount of rainfall recorded in 2015-16, especially in June. Furthermore, the infil parameter (water infiltrability at the base of each soil layers, $\mathrm{mm}$ /day) is estimated as a function of textural classes from the pedotransfer table presented in Brisson et al. (2008) and based on Jamagne et al. (1977). The same soil description was used for all treatments and for both growing seasons.

For each growing season, the same crop management file (sowing date, depth and density, dates and amounts of $\mathrm{N}$ rate supply, date and depth of soil tillage) was used for the three treatments. The climatic,
Table 1

Soil description for each layer.

\begin{tabular}{|c|c|c|c|c|c|c|c|}
\hline \multirow{3}{*}{$\begin{array}{l}\text { Layer tick } \\
{[\mathrm{m}]}\end{array}$} & \multicolumn{4}{|c|}{ Field measurement } & \multicolumn{3}{|c|}{ Pedotransfer function } \\
\hline & \multirow{2}{*}{$\begin{array}{l}\text { Clay } \\
\text { [\%] }\end{array}$} & \multirow{2}{*}{$\begin{array}{l}\text { Silt } \\
\\
{[\%]}\end{array}$} & \multirow{2}{*}{$\begin{array}{l}\text { Sand } \\
\text { [\%] }\end{array}$} & \multirow{2}{*}{$\begin{array}{l}\text { Bulk } \\
\text { density }\end{array}$} & \multicolumn{2}{|c|}{$\begin{array}{l}\text { Gravimetric water } \\
\text { content }\end{array}$} & \multirow{2}{*}{$\begin{array}{l}\text { Infil } \\
{[\mathrm{mm} / \mathrm{d}}\end{array}$} \\
\hline & & & & & $\begin{array}{l}\text { at field } \\
\text { capacity } \\
{[\%]}\end{array}$ & $\begin{array}{l}\text { at wilting } \\
\text { point } \\
{[\%]}\end{array}$ & \\
\hline $0-25$ & 10 & 84.5 & 5.5 & 1.3 & 19.38 & 9.23 & 2.25 \\
\hline $25-50$ & 15.75 & 80.75 & 3.5 & 1.5 & 16.33 & 7.53 & 6.91 \\
\hline $50-70$ & 14.75 & 81.75 & 3.5 & 1.53 & 16.34 & 7.71 & 7.00 \\
\hline $70-100$ & 14.5 & 82.5 & 3.0 & 1.53 & 18.00 & 9.48 & 3.45 \\
\hline $100-150$ & 14 & 83.5 & 2.2 & 1.53 & 20.32 & 11.81 & 3.33 \\
\hline
\end{tabular}

soil and management inputs file used in this study are available in zenodo.org with DOI 10.5281/zenodo.800568.

In addition, STICS requires specific plant parameters. The majority of these parameters have been formulated to be generic to the species and others are cultivar-dependent (13 parameters). The complete list of model parameters and input variables is given in Brisson et al. (2008). Preliminary calibration of the plant parameters set was performed by Dumont et al. $(2014,2015,2016)$ on a closely related cultivar (Julius) within a wide range of management and environmental conditions in the Hesbaye region.

\subsection{Plant parameters calibration}

The calibration was performed using only the field data from the NS treatment of both growing seasons. That means that the data set was split in two in order to on the one hand optimize the parameters using regular conditions of crop growth (no shade) and on the other hand to keep an independent data set composed of observations under the shaded treatments for the model evaluation.

\subsubsection{Phenological stage and grain yield threshold parameters}

From the initial set of parameters calibrated by Dumont et al. (2014, 2015, 2016), some cultivar parameters were manually adjusted following field observed values. The cultivar parameters involved in the prediction of the vegetative (stlevamf, stamflax and stlevdrp) and reproductive (stdrpmat) phenological stages, as well as yield component threshold parameters (pgrainmax and nbgrmax) were adjusted according to field observations done under the NS treatment during both growing seasons as explained above (Table 2). The remaining parameters were fixed to the default value provided in STICS model (Brisson et al., 2008). The complete plant parameter file used in this study is available in zenodo.org with DOI 10.5281/zenodo.800568.

Table 2

Value of the plant parameters defined in STICS model (initial set) and calibrated on the NS treatment data of both experimental years (calibrated set).

\begin{tabular}{|c|c|c|c|c|}
\hline & Range & Initial set & Calibrated set & Unit \\
\hline \multicolumn{5}{|c|}{ Adjustement from field observation } \\
\hline stlevamf & $0-6000$ & 315 & 260 & ${ }^{\circ} \mathrm{C}$. days \\
\hline stamflax & $0-6000$ & 325 & 275 & ${ }^{\circ} \mathrm{C}$.days \\
\hline stlevdrp & $0-6000$ & 700 & 790 & ${ }^{\circ} \mathrm{C}$.days \\
\hline stdrpmat & $0-6000$ & 850 & 800 & ${ }^{\circ} \mathrm{C}$.days \\
\hline nbgrmax & $0-1.10^{6}$ & 28000 & 29000 & grain $/ \mathrm{m}^{2}$ \\
\hline pgraimaxi & $0.003-0.5$ & 0.05 & 0.042 & $\mathrm{~g}$ \\
\hline$v_{i t i c a r b}$ & $5.10^{-5}-0.002$ & 0.007 & 0.0065 & $\begin{array}{l}\text { g grain/g plant/ } \\
{ }^{\circ} \text { C.days }\end{array}$ \\
\hline \multicolumn{5}{|c|}{ Calibration from linear regression } \\
\hline cgrain & $0.01-1$ & 0.045 & 0.0298 & grains/g.day \\
\hline cgrain $_{v o}$ & $-15.10^{3}$ to $15.10^{3}$ & 0 & 0.1546 & - \\
\hline nbjgrain & $5-40$ & 30 & 12 & day \\
\hline
\end{tabular}


In the field, we observed a mismatch between the occurrence of the maturity stage under the CS treatment and the NS treatment. Given the STICS formalism and the literature on the subject, it appeared that the temperature, which is the main driver of the phenological development in the model, had to be corrected. In the STICS formalism, the duration between two phenological stages, i.e. between idrp (day of beginning of grain filling, julian day) and imat (days of physiological maturity, julian day), is expressed in degree-days and calculated on the basis of crop temperature (TCULT). This crop temperature relies on the daily sum of evaporative fluxes, the calculation of net radiation and the air temperature. This daily crop temperature is calculated as the arithmetic mean of the maximum and minimum crop temperature both depending, amongst others, on the maximum and minimum air temperature (Tmax and Tmin, ${ }^{\circ} \mathrm{C}$ ) assumed to occur at midday and at the end of the night, respectively. Given the experimental observation, the main difference between non-shaded and shaded treatments is a reduction of the maximal air temperature rather than of the minimal air temperature. Unfortunately the experimental set-up did not included temperature sensors under the three treatments (CS, PS and NS). Therefore, we propose to use the Eqs. (1) and (2) to correct the temperature series that were used to run the model.

$$
\begin{aligned}
\text { Temp reduction }= & \frac{\text { stdrpmat }+ \text { stshadedrp }}{\text { ndshademat } N S \text { treatment }} \\
& -\frac{\text { stdrpmat }+ \text { stshadedrp }}{\text { ndshademat } C S \text { treatment }}
\end{aligned}
$$

Tmax reduction $=2 x$ Temp reduction

In this equation, the parameter stdrpmat (degree.days) corresponds to the duration between the idrp (day of beginning of grain filling, julian day) and imat (day of physiological maturity, julian day) stage; stshadedrp (degree.days) corresponds to the duration between the first day of shade application and the idrp stage; ndshademat defines the number of days between the first day of shade application and the imat stage for the NS treatment and the CS treatment. The maximal air temperature (Tmax, ${ }^{\circ} \mathrm{C}$ ) was recomputed using Eqs. (1) and (2) for the CS treatment, while NS and PS did not show delay in phenology. Thus, according to this adjusted value of Tmax and daily global radiation recorded under the CS treatments, TCULT was decreased under the CS treatments during periods with shade.

\subsubsection{Final grain yield parameters}

The calibration procedure on which this paper focuses implies the optimization of three species-dependent parameters involved in the grain number prediction, nbjgrain, cgrain and $\operatorname{cgrain}_{v o}$. First the nbjgrain parameter was fixed analyzing sensitivity of the response of the simulated mean canopy growth rate (vitmoy, $\mathrm{g} / \mathrm{m}^{2} / \mathrm{d}$ ) to different values of nbjgrain ranging from 0 to 30 days before flowering. Second, the two parameters cgrain and cgrain $_{v o}$ were optimized by linear regression on observed values. These two parameters are involved in the relation defining the proportion of actual grain number to the potential maximum number of grains (nbgrains/nbgrmax, axis y) as a function of average aboveground growth rate (vitmoy, $\mathrm{g} / \mathrm{m}^{2} / \mathrm{d}$, axis $\mathrm{x}$ ) during the prevailing period of grain filling (nbjgrain). To perform this linear regression, the daily biomass accumulation (dltams $\mathrm{t} / \mathrm{ha}$ ) was simulated for the NS treatments of both growing seasons. Then, the vitmoy variable was calculated as the ratio of this simulated dltams and the nbjgrain parameter, which was fixed at 12 days. Thereafter, the ratio nbgrain$\mathrm{s}_{\mathrm{obs}} /$ nbgrmax was defined using the observed grain number under each treatment in the field (nbgrains obs $_{\text {) }}$ and a fixed value of the parameter nbgrmax.

\subsection{Model evaluation under the shaded conditions}

The ability of STICS to predict the total aboveground biomass, final yield and yield components was tested by comparing the model estimation, calibrated on the NS treatment datasets, to the experimental field observations including the datasets of the PS and CS shade treatments during the two growing seasons. The statistical criteria used to evaluate the model performance were the root mean square error (RMSE), the Nash-Sutcliffe efficiency (NSE) and the pBias criterion. The RMSE gives the standard deviation of the model prediction error (Eq. (3)). The lower the RMSE values are (same unit as the variable), the better is the model prediction. The NSE is a normalized statistic which determines the relative magnitude of the residual variance compared to the measured data variance (Eq. (4)). This criterion varies from 1 to the negative infinite value, with NSE $=1$ being the optimal value. The closer the NSE value to 1 , the more accurate the model prediction. Values below 0 mean that the mean observed value is a better predictor than the simulated one, and the performance of the model is judged unacceptable.

The pBias measures the average tendency of simulated values to be larger or smaller compared to the observed ones (Eq. (5)). The optimal value of the pBias is 0 , while positive and negative values indicate a model under- and overestimation.

$R M S E=\sqrt{\frac{1}{n} \sum_{i=1}^{n}(\mathrm{yi}-\widehat{y i})^{2}}$

$N S E=1-\frac{\sum_{i=1}^{n}(y i-\widehat{y i})^{2}}{\sum_{i=1}^{n}(y i-\bar{y})^{2}}$

pias $=100 * \frac{1}{n} \sum_{i=1}^{n}(\widehat{y i}-y i)$

Where $n$ is the total number of measurements, $y i$ is the measured value for the ith measurement, $\bar{y}$ is the average of the measured value, and $\widehat{y i}$ is the simulated value for the ith measurement.

\section{Results}

\subsection{Impact of shade on wheat growth and yield: field observations}

Winter wheat experienced similar light conditions before its $\mathrm{LAI}_{\max }$ stage in both years, so no important differences in phenological development should be expected due to that factor. Then, from flowering to harvest, the cumulated global radiation received by the crop under the CS treatment was reduced by $65 \%$ in $2014-15$ and $56 \%$ in $2015-16$. For the PS treatment, it varied from 55\% to $35 \%$ in $2014-15$ and from $46 \%$ to $31 \%$ in $2015-16$. In $2014-15$, these contrasted conditions resulted in a phenological time lag between the treatments. We observed a mismatch of 7 days between the occurrence of the maturity under the CS treatment (5 August 2015) and the NS and PS treatment (29 July 2015). In other words, under the NS and PS treatment the interval between flowering and maturity was 45 days, while it was 52 days under the CS treatment. In 2016, the phenological delay was observed but not quantified.

This reduction of the available incident global radiation under the CS and PS treatments led to a decrease of the final aboveground biomass as compared to the NS treatment (Fig. 2). For both growing seasons, the difference between the treatments was mainly due to a significant reduction of spike biomass under the shade treatments (Table 3). At harvest, the total aboveground biomass under the shade treatments was significantly reduced as compared to the NS treatment (Fig. 2).

The reduction of the global radiation received by the crop mainly affected yield elaboration processes with detrimental consequences for the final grain yield $(\mathrm{t} / \mathrm{ha})$ and grain number per $\mathrm{m}^{2}$. Table 3 presents the mean value of the final grain yield and the yield components observed under the NS treatment and the relative reduction of the values of these variables under the CS and PS treatments. At harvest, in 

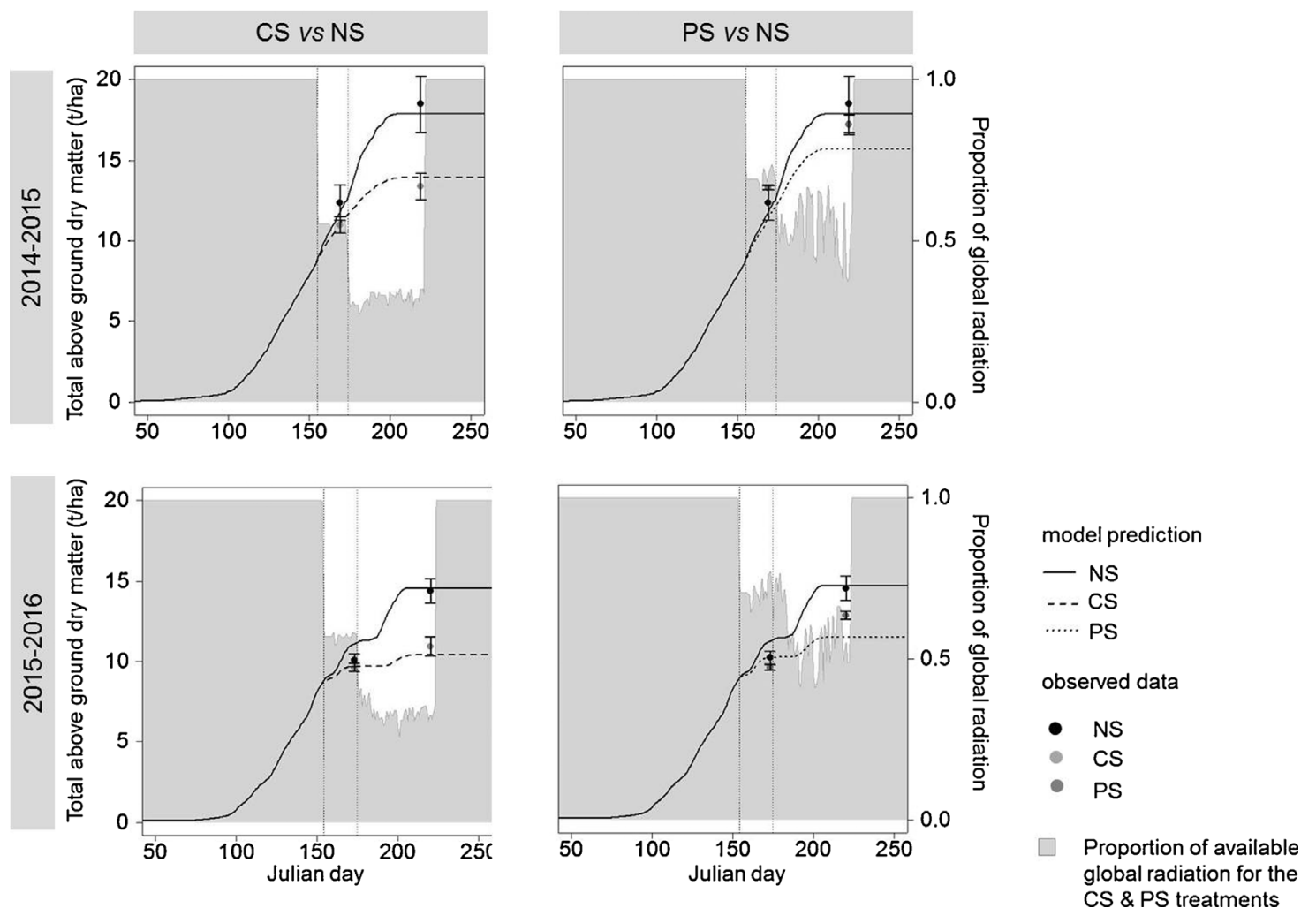

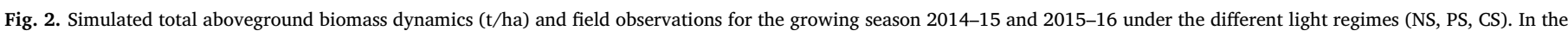

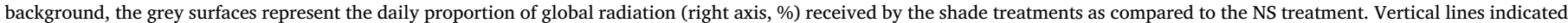
the date of the shade layers applications during the cropping seasons. Vertical bars represent the standard error of the means of the observed data.

2014-15 and 2015-16, we observed a significant yield reduction for the CS and PS treatment in comparison to the NS treatment (Table 3). This decrease was related to a significant reduction of both grain weight and grain number under the CS and PS treatments as compared to the NS treatment. Moreover, grain size calibration reveals that under the NS treatment, the final grain yield mainly relies on large grains $(<2.5 \mathrm{~mm}$ and $<2.8 \mathrm{~mm}$ : $84 \%$ in $2014-2015$ and $66 \%$ in $2015-16)$ and a small proportion of medium $(<2.5 \mathrm{~mm}$ and $>2.8 \mathrm{~mm}: 10 \%$ in $2014-2015$ and $23 \%$ in 2015-16) and small grain sizes $(<2.2 \mathrm{~mm}$ and $<2.5 \mathrm{~mm}$ : $3 \%$ both growing season). Nevertheless, these proportions change when wheat is exposed to a shade treatment. Under the CS treatments, the final grain is composed by on average $31-26 \%$ of large grain, $39-44 \%$ of medium grain and by 8-6\% of small grain, respectively for the season 2014-15 and 2015-16. Under the PS shade treatment, we observe $65 \%-36 \%$ of large grains, $22 \%-36 \%$ of medium grains and $8-21 \%$ of small grains size. As a consequence, shading significantly decreased the harvest index (HI) at maturity (Table 3). The large differences in observed aboveground biomass dynamics and final yield between the 2 years can be explained by a reduction of the available global radiation and an important waterlogging event in 2016 with particularly unfavorable weather conditions for winter wheat during the grain setting and the grain filling period (Fig. 2).

\subsection{Plant parameters calibration}

\subsubsection{Phenological stage adjustment}

When using the set of phenological parameters adjusted under NS conditions (Table 2), the time to reach maturity for harvest under the PS treatment was well predicted. However, under the CS treatments it was reached seven days earlier in the simulation than observed in the

Table 3

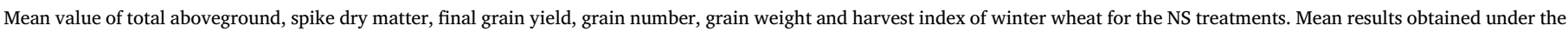
PS and CS treatments are expressed in percentage of the nominal NS treatment. Statistical significance of the equality between treatments is represented by the $p$ - $v a l u e$.

\begin{tabular}{|c|c|c|c|c|c|c|c|c|}
\hline & & \multicolumn{2}{|c|}{ Total aboveground dry matter $[\mathrm{t} / \mathrm{ha}]$} & \multirow{2}{*}{$\begin{array}{l}\text { Spike dry matter [t/ } \\
\text { ha] } \\
\text { at harvest }\end{array}$} & \multirow[t]{2}{*}{ Grain yield [t/ha] } & \multirow{2}{*}{$\begin{array}{l}\text { Grain number } \\
{\left[\# / \mathrm{m}^{2}\right]}\end{array}$} & \multirow[t]{2}{*}{ Grain weight $[\mathrm{g}]$} & \multirow[t]{2}{*}{ Harvest index [/] } \\
\hline & & at flowering & at harvest & & & & & \\
\hline \multirow[t]{4}{*}{$2014-15$} & NS & 12.34 & 18.47 & 10.94 & 9.94 & 23788 & 0.042 & 0.55 \\
\hline & $\begin{array}{l}\text { PS [in } \% \text { of } \\
\text { NS] }\end{array}$ & $+7.77 \%$ & $-6.87 \%$ & $-12.06 \%$ & $-20.82 \%$ & $-9.54 \%$ & $-11.90 \%$ & $-16.36 \%$ \\
\hline & $\begin{array}{l}\text { CS [in } \% \text { of } \\
\text { NS] }\end{array}$ & $-11.10 \%$ & $-27.61 \%$ & $-36.83 \%$ & $-49.19 \%$ & $-24.78 \%$ & $-33.33 \%$ & $-30.90 \%$ \\
\hline & p-value & 0.12 & 0.03 & 0.02 & $7.84 .10^{-6}$ & 0.01 & $1.20 .10^{-7}$ & 0.017 \\
\hline \multirow[t]{4}{*}{$2015-16$} & NS & 10.06 & 14.38 & 8.08 & 6.10 & 14407 & 0.042 & 0.42 \\
\hline & $\begin{array}{l}\text { PS [in } \% \text { of } \\
\text { NS] }\end{array}$ & $-6.26 \%$ & $-11.05 \%$ & $-14.60 \%$ & $-17.37 \%$ & $-9.30 \%$ & $-7.14 \%$ & $-7.14 \%$ \\
\hline & $\begin{array}{l}\text { CS [in } \% \text { of } \\
\text { NS] }\end{array}$ & $-4.57 \%$ & $-23.99 \%$ & $-32.79 \%$ & $-35.90 \%$ & $-19.11 \%$ & $-19.04 \%$ & $-14.28 \%$ \\
\hline & p-value & 0.35 & $7.10^{-3}$ & $3.7 .10^{-7}$ & $1.10^{-4}$ & 0.01 & $2.10^{-4}$ & 0.0024 \\
\hline
\end{tabular}


field. To correctly reproduce the delay which occurred in reality, the daily mean air temperatures have been reduced during the shading period, by adjusting the sole observed maximal temperature, following the Eq. (1). We reduced the daily mean air temperature by $1.96{ }^{\circ} \mathrm{C}$ by applying a reduction of $3.92{ }^{\circ} \mathrm{C}$ on the sole maximal air temperature input (Eq. (2)).

Temp reduction $=\frac{800+158}{55}-\frac{800+158}{62}=1.96^{\circ} \mathrm{C}$

Tmax reduction $=3.92{ }^{\circ} \mathrm{C}$

In 2014-15, TCULT was reduced by $2.79^{\circ} \mathrm{C}$ on average during the shade period under the CS as compared to the NS treatment. Likewise, in 2015-16, TCULT was reduced by $2.72{ }^{\circ} \mathrm{C}$ on average during the shade period under the CS as compared to the NS treatment. Under the CS treatment, the proposed reduction of the daily maximal air temperature showed good efficiency to improve the prediction of the grain maturity stage. This adjustment allowed to extend the grain filling period by 7 days in 2015, maturity reach on the 5th of august and 8 days in 2016, maturity reach on the 2nd of august as compared to the NS treatment, which was close to the field observations.

\subsubsection{Impact of nbjgrain, cgrain and cgrain $_{v o}$ parameters on final grain} number

Fig. 3 presents the variation of the average plant growth (vitmoy) as a function of the length of the observed period of growth prior to flowering (nbjgrain). Results are reported for the NS treatments and both growing seasons. The graph shows that in case a value of nbjgrain lower than 5 or greater than 18 days would have been used, the predicted vitmoy would have been too slightly responsive. This would have furthermore led to unrealistic optimization of the cgrain and cgrain $_{v o}$ parameter values. Contrarily, vitmoy appeared highly sensitive when nbjgrain ranges from 6 to 17 days. More precisely, vitmoy achieves a maximal value during the season 2014-15 at nbjgrain equaling 12 days and a minimal value the following season when nbjgrain equals 8 . In order to maximize the contrast within the responses of vitmoy we would recommend to select a value in between those thresholds; we arbitrarily fixed the nbjgrain parameter at 12 days (vertical solid line in Fig. 3). Fig. 4 and Table 2 present the default species parameter values proposed in STICS and the adjusted cgrain and cgrain $_{v o}$ using linear regression applied on the relationship between vitmoy and nbgrains ${ }_{\text {obs }} /$ nbgrmax, with the nbjgrain parameter fixed at 12 days.

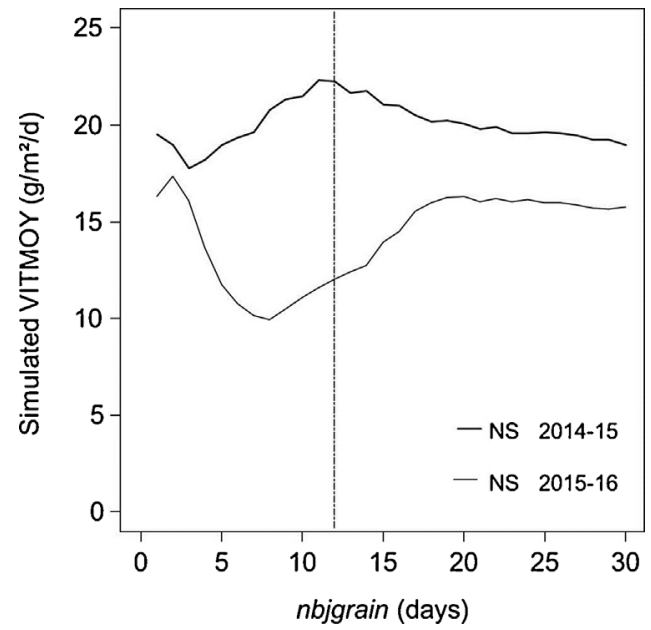

Fig. 3. Sensibility of the mean canopy growth rate (VITMOY, $g / \mathrm{m}^{2} / \mathrm{d}$ ) to the number of days prevailing grain filling period (nbjgrain, days). The vertical bar indicate the number of days fixed in this study to compute the grain number, nbjgrain $=12$ days.

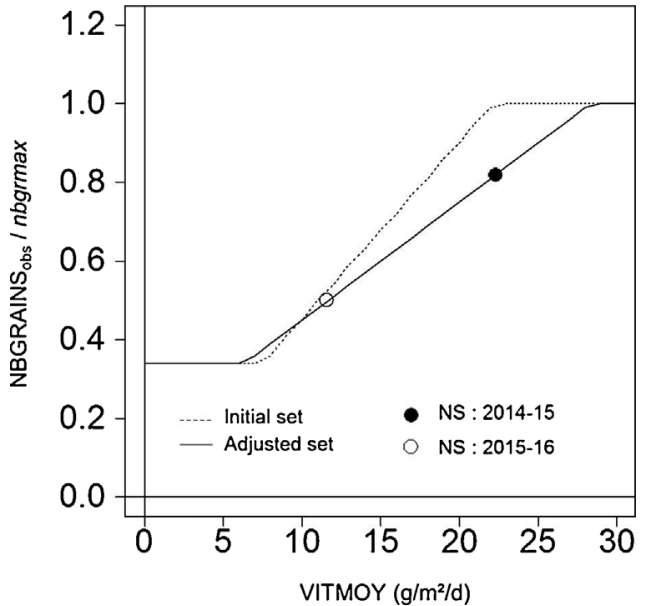

Fig. 4. Calibration of the parameters cgrain and cgrainvo from NS treatment observed data. These two parameters are respectively defined as the slope and the intercept of the regression between the proportion of grain number (NBGRAINS $_{\text {obs }} /$ nbgrmax) and plant growth (VITMOY) during the pre-grain filling period. The dashed line represent this relation for the initial set of plant parameter (cgrain $=0.045$, cgrainvo $=0$, nbjgrain $=30$ days $)$ and the solid line result from the adjustment from the observed data (cgrain $=0.0298$, cgrainvo $=0.1546$ and nbjgrain $=12$ days $)$.

\subsection{Model evaluation}

\subsubsection{Prediction of the aboveground biomass dynamics}

Overall, the simulations of the total aboveground biomass dynamics reflected the rank observed in the field experiment between the shade treatments. Nevertheless, detailed examination of the different treatments showed that at harvest the relative reduction of the total aboveground biomass for the PS treatment was higher in the simulation $(-12.19 \%$ in 2015 and $-22.29 \%$ in 2016$)$ than in the field $(-6.87 \%$ in 2015 and $-11.05 \%$ in 2016). Under the CS treatment in 2015 this reduction was smaller in the simulation $(-22.20 \%)$ than in the field $(-27.61 \%)$, while in 2016 is was higher in the simulation $(-28.66 \%)$ than in the field $(-23.99 \%$ ) (Fig. 2, Table 4). On average the total aboveground biomass prediction for the PS and CS datasets was good, the RMSE equaled 1.02 and $1.08 \mathrm{t} / \mathrm{ha}$, the NSE was 0.57 and 0.77 , and the pbias was -2.7 and $-5.3 \%$, at flowering and at harvest, respectively (Table 4).

\subsubsection{Prediction of final yield and yield components}

Overall, the simulations reflected the trends observed in the field experiment, with a decrease of the final grain yield and the grain number per $\mathrm{m}^{2}$ with increasing shade level. The calibration procedures clearly improved the agreement between simulated and measured values for the grain number component (Fig. 5): using the adjusted plant parameter set for the shaded treatment allowed to increase the model efficiency up to 0.96 and to reduce RMSE from 4882 to 749 grains per

Table 4

Root mean square error (RMSE), model efficiency (NSE) and pBias of the predicted aboveground dry matter at flowering and at harvest for the calibration dataset and validation dataset.

\begin{tabular}{|c|c|c|c|c|}
\hline & \multicolumn{2}{|l|}{ Calibration set } & \multicolumn{2}{|l|}{ Validation set } \\
\hline & \multicolumn{2}{|c|}{$\begin{array}{l}\text { NS treatment } 2014-15 \text { and } \\
2015-16\end{array}$} & \multicolumn{2}{|c|}{$\begin{array}{l}\text { CS \& PS treatment } 2014-15 \text { and } \\
2015-16\end{array}$} \\
\hline & $\begin{array}{l}\text { DM at flowering } \\
\text { [t/ha] }\end{array}$ & $\begin{array}{l}\text { DM at harvest } \\
\text { [t/ha] }\end{array}$ & $\begin{array}{l}\mathrm{DM} \text { at flowering } \\
\text { [t/ha] }\end{array}$ & $\begin{array}{l}\text { DM at harvest } \\
\text { [t/ha] }\end{array}$ \\
\hline RMSE & 0.82 & 0.44 & 1.02 & 1.08 \\
\hline NSE & 0.48 & 0.95 & 0.57 & 0.77 \\
\hline pBias & 2 & -1.2 & -2.7 & -5.3 \\
\hline
\end{tabular}



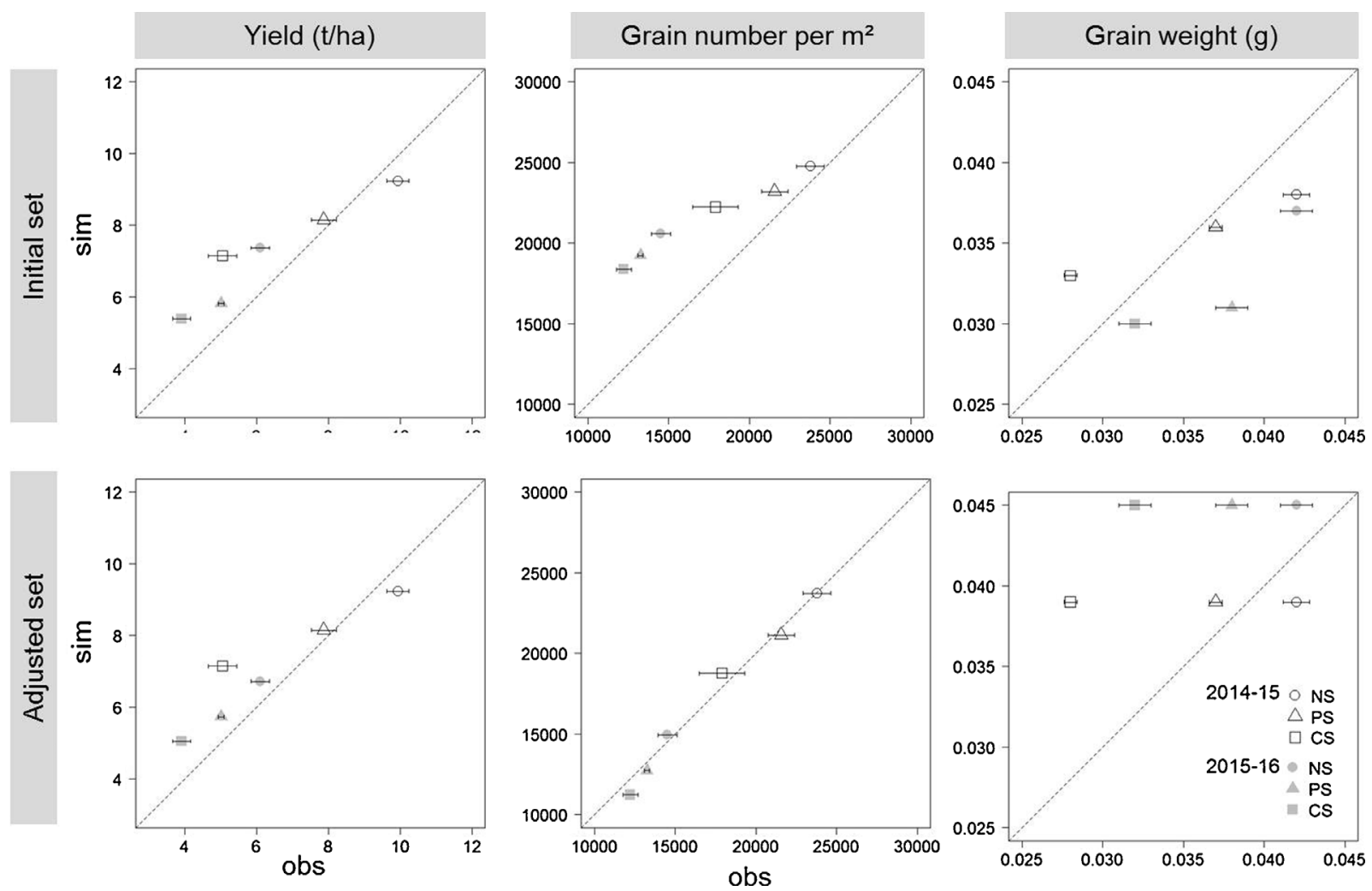

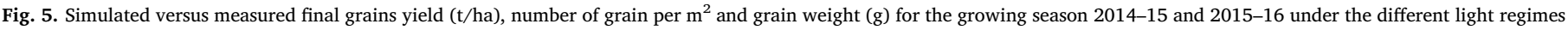
(NS, PS, CS) using the initial and adjusted plant parameter sets. Horizontal bars represent the standard error of the mean of the mean observed data.

\section{Table 5}

Root mean square error (RMSE), model efficiency (NSE) and pBias of the predicted yield, grain number and grain weight with the initial and adjusted plant parameters set for the calibration dataset and validation dataset.

\begin{tabular}{|c|c|c|c|c|c|c|}
\hline & \multicolumn{3}{|c|}{ Calibration set } & \multicolumn{3}{|c|}{ Validation set } \\
\hline & \multicolumn{3}{|c|}{$\begin{array}{l}\text { NS treatment } 2014-15 \text { and } \\
2015-16\end{array}$} & \multicolumn{3}{|c|}{$\begin{array}{l}\text { CS \& PS treatment 2014-15 and } \\
2015-16\end{array}$} \\
\hline & $\begin{array}{l}\text { Yield } \\
\text { [t/ha] }\end{array}$ & $\begin{array}{l}\text { Grain } \\
\text { number } \\
{\left[\# / \mathrm{m}^{2}\right]}\end{array}$ & $\begin{array}{l}\text { Grain } \\
\text { weight } \\
{[g]}\end{array}$ & $\begin{array}{l}\text { Yield } \\
\text { [t/ha] }\end{array}$ & $\begin{array}{l}\text { Grain } \\
\text { number } \\
{\left[\# / \mathrm{m}^{2}\right]}\end{array}$ & $\begin{array}{l}\text { Grain } \\
\text { weight } \\
{[\mathrm{g}]}\end{array}$ \\
\hline \multicolumn{7}{|c|}{ Initial set } \\
\hline RMSE & 1.02 & 4341 & 0.004 & 1.35 & 4882 & 0.004 \\
\hline NSE & 0.71 & 0.12 & & 0.14 & -0.69 & -0.22 \\
\hline pBias & 3.6 & 18.4 & -10.7 & 21.4 & 27.9 & -3.7 \\
\hline \multicolumn{7}{|c|}{ Adjusted set } \\
\hline RMSE & 0.66 & 299 & 0.003 & 1.25 & 749 & 0.009 \\
\hline NSE & 0.88 & 0.99 & & 0.26 & 0.96 & -4.2 \\
\hline pBias & -0.5 & 0.9 & 0 & 19.4 & -1.7 & 24.4 \\
\hline
\end{tabular}

$\mathrm{m}^{2}$ for the validation set (Table 5). A slight underestimation was still present for the season 2015-16 (Fig. 5). Nevertheless, the prediction on the final grain yield gave very similar results using both types of parameter sets. On the validation dataset, yield was slightly overestimated for all the treatments (Fig. 5, Table 5). Furthermore, the model failed to reproduce the field observation trend for the grain weight component and this regardless of the plant parameters used (Fig. 5). Apart from the NS treatment in 2015, grain weight was overestimated for all the other treatments (Fig. 5). For the growing season 2015-14, grain number was not involved in the grain yield determination as the simulated final grain yield (NS $=9.24$; $\mathrm{PS}=8.15$ and $\mathrm{CS}=7.14 \mathrm{t} / \mathrm{ha}$ ) did not exceed the pgrainmaxi $\mathrm{x}$ nbgrains limit, equal to $10.68,9.51$ and $8.46 \mathrm{t} /$ ha for the NS, PS and CS treatments respectively. For the season 2015-16, considering that the number of grains (nbgrains) was correctly simulated, one can conclude that the final grain yield has been bounded by the pgrainmaxi parameters value.

As a reminder, only one value of pgrainmaxi was used to account for the cultivar (adjusted based on the NS treatment dataset). We acknowledge that better results would have been obtained by adapting this parameter for the PS and CS treatment. This could have been justified by the different physiological trait (or the difference in phenotype) expressed by a plant exposed to contrasted light environment, but would have been contradictory with the genericity of the STICS model.

\section{Discussion}

\subsection{Impact of shade on winter wheat phenology, growth and final yield}

Field observations showed that applying a shade treatment during a pre- (7-10 days) and post-flowering period of winter wheat leads to a decrease of the overall plant biomass as well as a decrease of the grain number per $\mathrm{m}^{2}$ and the final grain weight. This is in accordance with a large body of literature on the subject (Artru et al., 2017; DemotesMainard and Jeuffroy, 2004; Dufour et al., 2013; Fischer, 1985; Sinclair and Jamieson, 2006). The literature suggests that the final grain yield depends on the grain number determination and on the remobilization of the pre-flowering reserve as well as on the photosynthesis occurring during the grain filling period (Bijanzadeh and Emam, 2010; Boiffin and Caneill, 1981; Gate, 1995).

From a physiological point of view, the shade treatment applied in this study occurred during three critical periods for the final grain yield elaboration: (i) the grain number settings period, just before flowering; (ii) the cell production phase, from flowering until around 14 days after flowering; and (iii) the cell expansion phase, from around 14 days after flowering until maturity (Brocklehurst et al., 1978). In our field experiment, the shade treatments influenced the composition of final grain yield in terms of grain number and grain size proportion. The larger amount of medium grain sizes $(<2.5 \mathrm{~mm})$ under the CS 
treatment as compared to the NS treatment may be due to either a diminution of cell productions per grain or a reduction of the cell expansion during the filling stage or both. Nevertheless, large grain size has also been observed under CS treatment certainly meaning that under shade treatment some grains present an equivalent number of cells and assimilate. In fact, field studies have shown that, although these components are developed sequentially, there can be some compensatory processes between the different yields components, with the prior-established components influencing the later-formed ones (Beed et al., 2007; Fischer, 2008; Jocković et al., 2014; Singh and Jenner, 1984). As for the grain number component, there is an unresolved ongoing debate on the relative importance of sink and source functions in the final yield determination. Some authors stipulate that grain number is implied in the regulation of the amount of resources accumulated in the grain during the grain filling period (Fischer, 2008), while others found that the grain number is a consequence of the accumulated resources, just like grain weight (Sinclair and Jamieson, 2006, 2008).

\subsection{Model calibration and evaluation}

We evaluated the ability of the crop model STICS to accurately predict winter wheat growth and yield under two reduced light environments using a common plant parameter set pre-calibrated on an independent dataset under full light conditions (NS treatment).

This study clearly demonstrates that STICS results in an accurate prediction of the total aboveground biomass dynamics under a constant shade pattern of light using the daily global radiation as climatic input. Nevertheless, the model consistently underestimates the total aboveground biomass when using a daily cumulated global radiation for the PS treatment. These results raise questions about the validity of the relationship between the daily biomass accumulation and the intercepted global radiation for plants growing under intermittent shade regimes within a day. Furthermore, in STICS, the ratio of direct to diffuse irradiance is only computed as a function of the latitude and the date, while under shade treatments this ratio changes with higher proportions of diffuse irradiance as compared to direct light and this may induce variation in crop RUE (Sinclair et al., 1992). In STICS model, the radiation use efficiency parameter defined in the plant parameters set was the same whatever the light treatment.

Differences in crop phenology due to differences in air temperature under shade and full light conditions are important to take into account. When we reduced only the global radiation in the model, the predicted maturity date in the CS treatment was seven days earlier than the date observed in the field in 2015. While doing this, the simulated crop temperature only slightly decreased under the shaded treatments as compared to the NS treatment. This highlights the necessity to take the changes in terms of air temperature into account in the modeling in addition to the light reduction in order to correctly reproduce the effect of shade on the crop temperature and thus on the thermal time that drives the understory crop phenology. In fact, several authors have reported that air temperature at crop canopy level is reduced under agroforestry systems as well as under artificial shade structures. At a daily time scale, temperature decreases at daytime and it gets warmer at night under shade structures than in open air (Gosme et al., 2016; Karki and Goodman, 2015). In mature agroforestry systems (15-20 years old plot), Gosme et al. (2016) found that in spring, when temperatures are high and when the trees have leaves, the daily average air temperature can decrease by $1.2{ }^{\circ} \mathrm{C}$ in the agroforestry plot as compared to the control plot. Likewise, Karki and Goodman (2015) recorded a maximum decrease of $3.8{ }^{\circ} \mathrm{C}$ in August under 15-20 years old loblolly pine. However, Marrou et al. (2013) showed that, under photovoltaic shelter, convective air movement allows to homogenize the mean daily air temperature and the crop temperature and thus no differences were observed as compared to the full sun treatment. Similarly to the PS treatment applied in our study, this photovoltaic system induced periodic shade during the day according to the light movement with the path of the sun. These results confirm the assumption that in our experiment, under CS the wheat probably experiences a lower ambient temperature as compared to the NS, while no differences were observed under the PS treatment. Thus, a decrease of around $2{ }^{\circ} \mathrm{C}$ to the daily mean air temperature applied in this study under the CS treatment is consistent with the range of values recorded in other studies.

In STICS, the grain number relies only on the rate of carbon accumulation prior to flowering and in our study this formalism allows to accurately predict the grain number under the NS as well as under the shaded treatments, although the calibration of the nbjgrain, cgrain and cgrain $_{v o}$ plant parameters was mandatory. By applying shade treatments, several authors have shown that the duration of the critical period of grain number establishment (nbjgrain parameter in STICS) lasts about 20-30 days prior to flowering (Abbate et al., 1997; DemotesMainard and Jeuffroy, 2004; Fischer, 1985). Within this period the magnitude of wheat response varies according to the level and the number of days of shade application. Furthermore, Fischer and Stockman (1980) identified a maximal reduction of grain number when shade was imposed around 10-13 days prior to flowering. Within this period, the grain number determination remains highly sensitive to environmental variations. Our results support this finding: the aboveground biomass growth rate appears highly sensitive when the period ranged between $8-15$ days before flowering.

Thereafter, the grain filling process starts once the grain number has been set and as in most of the current crop models, the final grain yield relies on the partitioning of the pre- and post-flowering resource accumulation using a harvest index increase rate. This approach has the advantage of globalizing the two sources of assimilates (current growth and remobilization), while remaining economical in terms of number of parameters. In STICS, in the option we chose, the proportion of biomass allocated to the grain linearly increases with thermal time through the vitircarb $_{t}$ (g.grain/g.biomass/dd) parameter. In this formalism, the grain number (simulated) and the maximum grain weight (fixed parameter) permit to bound the final grain yield, which allows to simulate consistent carbon allocation rate to the grain and avoid unrealistic remobilization level. The pgrainmaxi acts as a threshold parameter. It could have been reduced to fit the grain weight observe under each of the light treatments, but in that case the parameter set would have been different for each treatment, thus losing the genericity of the modelling work. In our simulations, too much biomass was allocated to the grain under the shade conditions for both growing seasons. The remaining differences between the predicted and observed final yield under the shaded treatment were presumably caused by an overestimation of the reallocation of the biomass between shoots and grains as simulated by STICS, on which the user has no hand in the case of determinate growing plants. The STICS yield parameter vitircarb $b_{t}$ is the main parameter in the model that can be involved in the overestimation of the final yield and as a consequence to an overestimation of the grain weight for the shade treatment by inducing a high partitioning rate of the aboveground biomass to the grain. In fact, this parameter has been fixed to $6.5 .10^{-4}$ whatever the light treatment, while in the field, several studies have shown that after anthesis this partitioning can be highly variable and depends on environmental conditions ( $\mathrm{Li}$ et al., 2013; Wheeler et al., 1996). For the season 2015-16, the predicted final yield is bounded: although the number of grains was satisfactorily predicted, final yield was overestimated by using the same pgrainmaxi value under the three treatments (fixed here at $0.045 \mathrm{~g}$ ). These final yield predictions are not consistent with our field observations and results reported in other studies show that applying shade treatments prior to flowering until maturity affects grain number as well as grain weight.

For both components (grain number and weight), the underlying physiological mechanisms remain unclear. The simplest yield formalism proposed in the STICS model allowed to accurately reproduce the grain number, but it overrides the complexity of the grain filling and 
thus failed to accurately predict the final grain yield under continuous and intermittent shade environments. The formalism failed to reflect possible variations in the contribution of either the reserve build up during the vegetation or the actual photosynthesis efficiency, in response to fluctuating growing conditions. To do so, Garcia de CortazarAtauri et al. (2010) proposes to use the yield formalism implemented in STICS for indeterminate growing plants. That formalism provides a more mechanistic description of the final grain yield elaboration by making a distinction between the grain number setting period, the cell division phase and the cell elongation phase in the grain.

\section{Conclusions}

We evaluated the ability of the STICS crop model to simulate the development and the final yield components of winter wheat growing under heterogeneous light environment using a common set of plant parameters. This was performed using field data from an artificial shade experiment producing three contrasted shade treatments (NS, PS, CS) on winter wheat during two growing seasons. We showed that the overall aboveground biomass was well predicted for all three treat- ments. However, under the CS treatment, the implementation of a reduction of the mean daily air temperature was necessary in addition to the reduction of the incident global radiation to accurately simulate the timing of the phenological stages. Regarding the final yield components, the calibration of three plant parameters involved in the grain number formalism was mandatory to accurately predict the grain number under the NS treatment as well as under the shade conditions. Nevertheless, final grain yield and thus grain weight remained overestimated under the continuous and periodic shade treatment. This inaccuracy relies on the STICS yield prediction formalism. In fact, the present formalization did not allow to adequately reflect the complexity of reserve partitioning occurring for plants growing under fluctuating shade conditions. Therefore, these results highlight the limits of the STICS model when used to simulate crop growth under contrasted shade conditions. Thus, further progress is necessary to accurately predict the complexity of the winter wheat development and yield under shade. An interesting next step would be to use the yield formalism used in STICS for indeterminate growing plants which involves a "sink strength" function and source/sink ratio.

\section{Appendix A}

Table A1

Definition and units of the variable and parameters.

\begin{tabular}{|c|c|c|}
\hline \multicolumn{3}{|l|}{ Names } \\
\hline dltams & Growth rate of the plant & t/ha/day \\
\hline dtags & Growth rate of the grains & t/ha/day \\
\hline iamf & Day of the maximal leaf growth stage & julian day \\
\hline idrp & Day of the beginning of grain filling stage & julian day \\
\hline ilax & Day of the maximum leaf area index stage & julian day \\
\hline ilev & Day of the emergence stage & julian day \\
\hline imat & Day of physiological maturity stage & julian day \\
\hline ircarb & Carbon harvest index & g grain/g plant \\
\hline mafruit & Dry matter of harvested organs & $\mathrm{t} / \mathrm{ha}$ \\
\hline masec & Aboveground dry matter & $\mathrm{t} / \mathrm{ha}$ \\
\hline nbgrains & Grain number & grains $/ \mathrm{m}^{2}$ \\
\hline pgrain & Grain weight & $\mathrm{g}$ \\
\hline vitmoy & $\begin{array}{l}\text { Average growth rate during the latence } \\
\text { phase }\end{array}$ & $\mathrm{g} / \mathrm{m}^{2} /$ day \\
\hline \multicolumn{3}{|c|}{ Parameters } \\
\hline \multicolumn{3}{|c|}{ Vegetative phenological stage } \\
\hline stlevamf & Duration between ilev and iamf & ${ }^{\circ} \mathrm{C}$.day \\
\hline stamflax & Duration between iamf and iflax & ${ }^{\circ} \mathrm{C}$. day \\
\hline stlevdrp & Duration between ilev and idrp & ${ }^{\circ} \mathrm{C}$.day \\
\hline \multicolumn{3}{|c|}{ Reproductive phenological stage } \\
\hline stdrpmat & Duration between idrp and imat & ${ }^{\circ} \mathrm{C}$.day \\
\hline \multicolumn{3}{|c|}{ Yield formation } \\
\hline cgrain & - & - \\
\hline cgrain $_{v o}$ & - & - \\
\hline nbjgrain & Period before idrp to compute grain number & ${ }^{\circ} \mathrm{C}$.day \\
\hline viticarb $_{t}$ & Rate of increase of the carbon harvest index & $\mathrm{g}$ grain/g plant/day \\
\hline$\frac{\text { Yield com }}{\text { nbgrmax }}$ & Maximum number of grains & grains $/ \mathrm{m}^{2}$ \\
\hline pgraimaxi & Maximum weight of one grain & $\mathrm{g}$ \\
\hline
\end{tabular}

\section{References}

Abbate, P.E., Andrade, F.H., Culot, J.P., Bindraban, P.S., 1997. Grain yield in wheat: effects of radiation during spike growth period. Field Crops Res. 54, 245-257.

Artru, S., Garré, S., Dupraz, C., Hiel, M.-P., Blitz-Frayret, C., Lassois, L., 2017. Impact of spatio-temporal shade dynamics on wheat growth and yield, perspectives for temperate agroforestry. Eur. J. Agron. 82, 60-70. http://dx.doi.org/10.1016/j.eja.2016.10.004.

Beed, F.D., Paveley, N.D., Sylvester-Bradley, R., 2007. Predictability of wheat growth and yield in light-limited conditions. J. Agric. Sci. 145, 63. http://dx.doi.org/10.1017/ S0021859606006678.
Bijanzadeh, E., Emam, E., 2010. Effect of source-sink manipulation on yield components and photosynthetic characteristic of wheat cultivar. J. Appl. Sci. 10, 564-569. Boiffin, J., Caneill, J., 1981. que régional.

Brisson, N., Itier, B., L'Hotel, J.C., Lorendeau, J.Y., 1998. Parameterisation of the Shuttleworth-Wallace model to estimate daily maximum transpiration for use in crop models. Ecol. Modell. 107, 159-169.

Brisson, N., Launay, M., Mary, B., Beaudoin, N., 2008. Conceptual Basis, Formalisations and Parametrization of the STICS Crop Model. Quae. ed. Versailles.

Brocklehurst, P.A., Moss, J.P., Watkin, W., 1978. Effects of irradiance and water supply on grain development in wheat. Ann. Appl. Biol. 90, 265-276.

Cannell, M.G.R., van Noordwijk, M., Ong, C.K., 1996. The central agroforestry hypothesis: 
the trees must acquire resources that the crop would not otherwise acquire. Agrofor. Syst. 34, 27-31.

Chimonyo, V.G.P., Modi, A.T., Mabhaudhi, T., 2015. Perspective on crop modelling in the management of intercropping systems. Arch. Agron. Soil Sci. 1-19. http://dx.doi.org/ 10.1080/03650340.2015.1017816.

Coucheney, E., Buis, S., Launay, M., Constantin, J., Mary, B., García de Cortázar-Atauri, I., Ripoche, D., Beaudoin, N., Ruget, F., Andrianarisoa, K.S., Le Bas, C., Justes, E. Léonard, J., 2015. Accuracy, robustness and behavior of the STICS soil-crop model for plant, water and nitrogen outputs: evaluation over a wide range of agro-environmental conditions in France. Environ. Modell. Softw. 64, 177-190. http://dx. doi.org/10.1016/j.envsoft.2014.11.024.

Demotes-Mainard, S., Jeuffroy, M.-H., 2004. Effects of nitrogen and radiation on dry matter and nitrogen accumulation in the spike of winter wheat. Field Crops Res. 87, 221-233. http://dx.doi.org/10.1016/j.fcr.2003.11.014.

Dufour, L., Metay, A., Talbot, G., Dupraz, C., 2013. Assessing light competition for cereal production in temperate agroforestry systems using experimentation and crop modelling. J. Agron. Crop Sci. 199, 217-227. http://dx.doi.org/10.1111/jac.12008.

Dumont, B., Leemans, V., Mansouri, M., Bodson, B., Destain, J.-P., Destain, M.-F., 2014. Parameter identification of the STICS crop model, using an accelerated formal MCMC approach. Environ. Modell. Softw. 52, 121-135. http://dx.doi.org/10.1016/j. envsoft.2013.10.022.

Dumont, B., Basso, B., Leemans, V., Bodson, B., Destain, J.-P., Destain, M.-F., 2015. Systematic analysis of site-specific yield distributions resulting from nitrogen management and climatic variability interactions. Precis. Agric. 16, 361-384.

Dumont, B., Basso, B., Bodson, B., Destain, J.-P., Destain, M.-F., 2016. Assessing and modeling economic and environmental impact of wheat nitrogen management in Belgium. Environ. Modell. Softw. 79, 184-196. http://dx.doi.org/10.1016/j.envsoft. 2016.02.015.

Fischer, R.A., Stockman, Y.M., 1980. Kernel number per spike in wheat (Triticum aestivum L.): responses to preanthesis shading. Funct. Plant Biol. 7, 169-180.

Fischer, R.A., 1985. Number of kernels in wheat crops and the influence of solar radiation and temperature. J. Agric. Sci. 105, 447-461.

Fischer, R.A., 2008. The importance of grain or kernel number in wheat: a reply to Sinclair and Jamieson. Field Crops Res. 105, 15-21. http://dx.doi.org/10.1016/j.fcr. 2007.04.002.

García-Barrios, L., Ong, C.K., 2004. Ecological interactions, management lessons and design tools in tropical agroforestry systems. Agrofor. Syst. 61, 221-236.

Garcia de Cortazar-Atauri, I., Launay, M., Brisson, N., 2010. Evaluation des formalismes du calcul du rendement des plantes déterminées: cas du blé tendre et du blé dur. INRA-Agroclim- Arvalis 29.

Gate, P., 1995. Ecophysiologie du blé: de la plante à la culture. Technique et Doc. Lavoisier, France, Paris.

Gosme, M., Aguirre, H.D.I., Dupraz, C., 2016. Microclimatic effect of agroforestry on diurnal temperature cycle. In: Presented at the 3rd European Agroforestry Conference. Montpellier, France.

Jamagne, M., Betremieux, R., Begon, J., Mori, A., 1977. Quelques données sur la variabilité dans le milieu naturel de la réserve en eau des sols. Bulletin Technique d'Information - Ministère de l'agriculture 324-325, 627-641.

Jocković, B., Mladenov, N., Hristov, N., Aćin, V., Djalović, I., 2014. Interrelationship of grain filling rate and other traits that affect the yield of wheat (Triticum aestivum L.). Roman. Agric. Res. 31, 81-87.

Jones, C.A., Bland, W.L., Ritchie, J.T., Williams, J.R., 1991. Simulation of Root Growth. pp. 91-123.

Karki, U., Goodman, M.S., 2015. Microclimate differences between mature loblolly-pine silvopasture and open-pasture. Agrofor. Syst. 89, 319-325.

Knörzer, H., Grözinger, H., Graeff-Hönninger, S., Hartung, K., Piepho, H.-P., Claupein, W., 2011. Integrating a simple shading algorithm into CERES-wheat and CERES-maize with particular regard to a changing microclimate within a relay-intercropping system. Field Crops Res. 121, 274-285. http://dx.doi.org/10.1016/j.fcr.2010.12.016.

Leroy, C., Sabatier, S., Wahyuni, N.S., Barczi, J.-F., Dauzat, J., Laurans, M., Auclair, D., 2009. Virtual trees and light capture: a method for optimizing agroforestry stand design. Agrofor. Syst. 77, 37-47. http://dx.doi.org/10.1007/s10457-009-9232-z.

Li, H., Cai, J., Jiang, D., Liu, F., Dai, T., Cao, W., 2013. Carbohydrates accumulation and remobilization in wheat plants as influenced by combined waterlogging and shading stress during grain filling. J. Agron. Crop Sci. 199, 38-48. http://dx.doi.org/10. 1111/j.1439-037X.2012.00532.x.

Liu, N., 1991. Light distribution in tree intercropping area and its agricultural value. Agroforestry Systems in China. pp. 14-21.

Luedeling, E., Smethurst, P.J., Baudron, F., Bayala, J., Huth, N.I., van Noordwijk, M., Ong, C.K., Mulia, R., Lusiana, B., Muthuri, C., Sinclair, F.L., 2016. Field-scale modeling of tree-crop interactions: challenges and development needs. Agric. Syst. 142, 51-69. http://dx.doi.org/10.1016/j.agsy.2015.11.005.

Malézieux, E., Crozat, Y., Dupraz, C., Laurans, M., Makowski, D., Ozier-Lafontaine, H., Rapidel, B., Tourdonnet, S., Valantin-Morison, M., 2009. Mixing plant species in cropping systems: concepts, tools and models. A review. Agron. Sustain. Dev. 29, 43-62. http://dx.doi.org/10.1051/agro:2007057.

Marrou, H., Guilioni, L., Dufour, L., Dupraz, C., Wery, J., 2013. Microclimate under agrivoltaic systems: is crop growth rate affected in the partial shade of solar panels? Agric. Forest Meteorol. 177, 117-132. http://dx.doi.org/10.1016/j.agrformet.2013. 04.012 .

Murchie, E.H., Niyogi, K.K., 2011. Manipulation of photoprotection to improve plant photosynthesis. Plant Physiol. 155, 86-92. http://dx.doi.org/10.1104/pp.110. 168831.

Palosuo, T., Kersebaum, K.C., Angulo, C., Hlavinka, P., Moriondo, M., Olesen, J.E., Patil, R.H., Ruget, F., Rumbaur, C., Takáč, J., Trnka, M., Bindi, M., Çaldă̆, B., Ewert, F., Ferrise, R., Mirschel, W., Şaylan, L., Šiška, B., Rötter, R., 2011. Simulation of winter wheat yield and its variability in different climates of Europe: a comparison of eight crop growth models. Eur. J. Agron. 35, 103-114. http://dx.doi.org/10.1016/j.eja. 2011.05.001.

Pearcy, R.W., Krall, J.P., Sassenrath-Cole, G.F., 1996. Photosynthesis in fluctuating light environments. Photosynthesis and the Environment. Springer, pp. 321-346.

Peri, P.L., McNeil, D.L., Moot, D.J., Varella, A.C., Lucas, R.J., 2002. Net photosynthetic rate of cocksfoot leaves under continuous and fluctuating shade conditions in the field. Grass Forage Sci. 57, 157-170.

Retkute, R., Smith-Unna, S.E., Smith, R.W., Burgess, A.J., Jensen, O.E., Johnson, G.N., Preston, S.P., Murchie, E.H., 2015. Exploiting heterogeneous environments: does photosynthetic acclimation optimize carbon gain in fluctuating light? J. Exp. Bot. 66, 2437-2447. http://dx.doi.org/10.1093/jxb/erv055.

Roupsard, O., Dauzat, J., Nouvellon, Y., Deveau, A., Feintrenie, L., Saint-André, L., Mialet-Serra, I., Braconnier, S., Bonnefond, J.-M., Berbigier, P., Epron, D., Jourdan, C., Navarro, M., Bouillet, J.-P., 2008. Cross-validating sun-shade and 3D models of light absorption by a tree-crop canopy. Agric. For. Meteorol. 148, 549-564. http:// dx.doi.org/10.1016/j.agrformet.2007.11.002.

Sinclair, T.R., Jamieson, P.D., 2006. Grain number, wheat yield, and bottling beer: an analysis. Field Crops Res. 98, 60-67. http://dx.doi.org/10.1016/j.fcr.2005.12.006.

Sinclair, T.R., Jamieson, P.D., 2008. Yield and grain number of wheat: a correlation or causal relationship? Field Crops Res. 105, 22-26. http://dx.doi.org/10.1016/j.fcr. 2007.07.003.

Sinclair, T.R., Shiraiwa, T., Hammer, G.L., 1992. Variation in crop radiation-use efficiency with increased diffuse radiation. Crop Sci. 32, 1281. http://dx.doi.org/10.2135/ cropsci1992.0011183X 003200050043x.

Singh, B.K., Jenner, C.F., 1984. Factors controlling endosperm cell number and grain dry weight in wheat: effects of shading on intact plants and of variation in nutritional supply to detached, cultured ears. Funct. Plant Biol. 11, 151-163.

Talbot, G., 2012. L'intégration spatiale et temporelle du partage des ressources dans un système agroforestier noyers-céréales: une clef pour en comprendre la productivité? Université Montpellier II.

Wheeler, T.R., Hong, T.D., Ellis, R.H., Batts, G.R., Morison, J.I.L., Hadley, P., 1996. The duration and rate of grain growth, and harvest index, of wheat (Triticum aestivum L.) in response to temperature and CO2. J. Exp. Bot. 47, 623-630.

van Noordwijk, M., Lusiana, B., 1999. WanNuLCAS 3.1. A model of water nutrient and light capture in agroforestry systems. Agrofor. Syst. 43, 217-242. 